\title{
Participação popular em saúde: um estudo sobre o conselho regional de saúde de Ceilândia, Distrito Federal-Brasil
}

\author{
Popular participation in health: a study on the health council of Ceilândia, Federal District \\ - Brazil
}

La participación popular en salud: un estudio sobre el consejo regional de salud en Ceilândia, Distrito Federal-Brasil

Andrecinda Rocha de Morais Pina ${ }^{1}$

RESUMO. Introdução: a questão da participação popular para o exercício do controle social do Sistema Único de Saúde é importante para o debate da política de saúde no Brasil e, conforme estabelecido na Lei Orgânica da Saúde de 1990. Essa participação deve ser realizada por meio dos conselhos e conferências de saúde. Este artigo discute a participação popular em saúde no Conselho Regional de Saúde de Ceilândia, Distrito Federal, em torno do exercício do controle social exercido pelos conselheiros. Teve por objetivo geral entender como se dá a participação social no Conselho Regional de Saúde de Ceilândia na gestão 2010-2011. Metodologia: utilizou-se uma abordagem metodológica qualiquantitativa, com procedimento de análise documental. Resultados: a maioria dos assuntos pautados foi proposta pelo segmento gestor. Os itens em discussão revelaram que os interesses dos usuários e trabalhadores permearam com mais frequência os debates. Conclusão: concluiu que o Conselho Regional de Saúde de Ceilândia é um fórum político legítimo e atuante, com atuação decisiva nas deliberações das ações e serviços de saúde a nível local.

Palavras-chave: Participação popular. Conselho de saúde. Controle social. Gestão participativa. Democracia.

ABSTRACT. Introduction: the popular participation for the social control in the Unified Health System is important for the health policy debate in Brazil. This participation should be carried out through councils and health conferences. This article discusses popular participation in health in the Health Council of Ceilândia, Distrito Federal, in order to discuss the exercise of the social control by the participants during the years 2010-2011. Methodology: was used a qualitative-quantitative methodological approach, with documentary analysis procedures. Results: most guided issues were proposed by the management segment. It revealed that the interests of users and workers are more often at permeated debates. Conclusion: it concluded that the Health Council of Ceilândia is a legitimate and active political forum, with a decisive role in the deliberations of the actions and health services at the local level.

Keywords: Popular participation. Health council. Social control. Participative management. Democracy

\footnotetext{
1 Graduada em Ciências Econômicas (UCB/DF). Graduada em Direito (UCB/DF). Especialista em Direito Público (Faculdade Processus/DF). E-mail: andrecindaro.pina@gmail.com
} 
RESUMEN. Introducción: el tema de la participación popular en el ejercicio del control social del Sistema Único de Salud es importante para el debate sobre las políticas de salud en Brasil. Esta participación debe llevarse a través de consejos y conferencias de salud. En este artículo se analiza la participación popular en la salud en el Consejo de Salud de Ceilândia, Distrito Federal, sobre el ejercicio del control social por los participantes. El propósito fue comprender la participación social en el Consejo Regional de Salud de Ceilândia en la gestión 2010-2011. Metodologia: se utilizó un enfoque metodológico cualitativo-cuantitativo, con el procedimiento de análisis documental. Los temas más frecuentes fueran propuestos por el segmento de gestión. Resultados: los elementos en debate revelaron que los intereses de los usuarios y de los trabajadores tuvieran más debates. Conclusión: se llegó a la conclusión de que el Consejo Regional de Salud Ceilândia es un foro político legítimo y activo, con un papel decisivo en las deliberaciones de las acciones y servicios de salud en el nivel local.

Palabras-llave: Participación popular. Consejo de Salud. Control social. Gestión participativa. Democracia

\section{Introdução}

A Constituição de 1988 (1), ao consolidar o Sistema Único de Saúde (SUS), insculpiu em seu texto o direito à participação da população no controle das políticas públicas de saúde. A Lei 8.142/90 (2) regulamentou esse direito, ou seja, a participação da comunidade na gestão do SUS.

$\mathrm{Na}$ organização dos serviços de saúde, conforme a lei supra, há a necessidade de incorporar a participação da população na formulação, fiscalização, execução e manutenção de políticas que visam atender as necessidades de cada localidade. Assim, foram pensados mecanismos institucionais, tais como os conselhos e conferências de saúde, para o exercício do controle social.

O SUS é regido por um conjunto de princípios, dentre eles o direito da participação social, pelo qual a população de forma democrática participa dos processos decisórios, por meio da fiscalização e desenvolvimento das políticas de saúde.

Neste sentido, o presente artigo tem como objetivo estudar a participação popular em saúde no Conselho Regional de Saúde de Ceilândia no Distrito Federal, problematizando em torno do exercício do controle social exercido pelos conselheiros do respectivo colegiado.

No Distrito Federal (DF), além do Conselho Distrital de Saúde, que tem as mesmas atribuições dos conselhos estaduais e municipais de saúde, existem os conselhos 
regionais de saúde, com atribuições menos burocráticas que aquele, na medida em que as Regiões de Saúde do DF são estruturas desconcentradas da Secretaria de Estado de Saúde do DF, como veremos adiante.

O objetivo geral deste estudo é discutir como se dá a participação social no Conselho Regional de Saúde de Ceilândia na gestão 2010-2011, tendo-se analisado a dinâmica de funcionamento do CRSC.

Com isto, pretende-se fornecer subsídios que permitam uma possível qualificação do trabalho dos conselheiros regionais de saúde de Ceilândia no exercício do controle social, de forma a contribuir para a melhoria da gestão pública, a nível local, tecendo-se assim, também, um panorama do controle social a partir das ações do Conselho Regional de Saúde.

\section{Democracia e participação popular: breve revisão}

O século XX apresentou ricos debates e discussões acerca do tema da democracia que resultaram em teorias que ora consideram a participação da sociedade fonte de desequilíbrio da democracia, ora consideram caminho para a justiça social. Até por força desse debate, tornou-se possível estudar novas formas de participação da sociedade civil (3).

Sendo o Brasil um país em fase de consolidação de sua democracia, já apresenta experiência de participação popular no que se refere à saúde, pois o Movimento de Reforma Sanitária nasceu e se desenvolveu em tempos não democráticos.

Assim, o direito à saúde, defendido na Reforma Sanitária, traz, intrinsecamente à sua constituição, o apoio, a participação e a pressão dos setores populares. Em outras palavras, o direito social de ter garantida a condição de saúde de uma população supõe o próprio movimento dessa população em conseguir o reconhecimento e a efetivação desse direito (4).

De outro modo: "A saúde define-se no contexto histórico de determinada sociedade e num dado momento de seu desenvolvimento, devendo ser conquistada pela população em suas lutas cotidianas" (5). Como bem destaca Alves (3), é no modelo democrático participativo que o cidadão deixa de ser mero expectador para ser ator principal no processo de construção política, pois neste modelo é imprescindível o 
envolvimento da população para reduzir desigualdades próprias do modo de produção capitalista, mas utilizando os mecanismos já disponíveis da democracia representativa.

Segundo Coelho et al (6), para ampliar o potencial de transformação social da democracia é preciso ir além da consolidação de suas dimensões formais e estruturais. Paralelamente à garantia constitucional de eleições regulares, partidos independentes, liberdade de expressão e associação, necessário se faz instituir mecanismos capazes de promover maior envolvimento dos cidadãos, maior transparência e um fluxo de informações mais amplo e horizontal nas decisões sobre políticas públicas (6).

Os conselhos surgem então como desdobramentos do movimento popular de saúde, consistindo em fóruns públicos para, entre outras coisas, reivindicação de melhorias no sistema de saúde (7). Tal movimento teve forte influência na proposição do Sistema Único de Saúde (SUS) e importante papel na redemocratização do país. Segundo o autor (7) sendo os conselhos fóruns participativos, podem ser analisados e pensados através da Teoria da Democracia Deliberativa.

Apesar da democracia ser um assunto amplamente debatido e aceito, é fluido e diversificado, o que requer uma breve apresentação dos fundamentos e conceitos associados ao termo para assim melhor demarcar a relação entre participação e deliberação popular, objeto deste trabalho (7).

Pode-se enquadrar esse debate sobre a democracia em duas grandes arenas: a liberal e a republicana. O primeiro grupo destaca a função de programar o Estado no interesse da sociedade - sendo o Estado o aparato de administração pública, e a sociedade o sistema de relações entre pessoas privadas e seu trabalho social, estruturados em termos de uma economia de mercado. Nesse sentido, a formação política dos cidadãos tem por função agregar e impor interesses sociais privados frente a um aparato estatal especializado no emprego administrativo do poder político, visando garantir fins coletivos (7)

Para os republicanos, por outro lado, a democracia não se esgota em um processo de mediação, sendo elemento constitutivo de todo o processo de formação da sociedade. Assim, a estruturação de espaços públicos, políticos e da sociedade civil assume o papel estratégico de garantir a força integradora e a autonomia da prática de entendimento entre os cidadãos (7). 
Desta compreensão de que a participação está fundamentada em noções de teoria econômica e democracia social, no sentido de dotar a convivência humana de maior equidade no acesso a bens materiais e culturais, extrai-se o desafio imposto à democracia representativa de desempenhar bem a representação e assegurar igualdade econômica e cultural, além de gerar formas eficientes de participação e deliberação popular no e acerca do Estado. (7).

Por outro lado, Figueiredo (8) define os Conselhos de Saúde (CS) como arranjos institucionais do setor saúde abertos à participação da sociedade civil organizada a partir das reformas setoriais que culminaram na criação do SUS.

Nessa linha, foi a partir de 1990, quando foram aprovadas as Leis 8.080 - Lei Orgânica da Saúde (9) e a 8.142/90 (2), que dispõe sobre os Conselhos de Saúde (CS) em âmbito nacional, que esses espaços passaram a fazer parte da organização do setor saúde, com a finalidade de materializar o cumprimento do princípio constitucional da "participação da comunidade" e também o controle social sobre as ações e serviços de saúde do SUS.

A Lei 8.142/90 (2) positiva esse controle, atribuindo aos CS caráter permanente e deliberativo e competências para participar "na formulação de estratégias e no controle da execução da política de saúde na instância correspondente, inclusive nos aspectos econômicos e financeiros, cujas decisões deverão ser homologadas pelo chefe do poder legalmente constituído em cada esfera do governo".

A Reforma Sanitária, movimento iniciado em meados da década de 70 , é uma proposta democratizante fundada nos princípios da equidade, na garantia da saúde como direito social e na construção de um poder local fortalecido pela gestão democrática. Incorporaram-se ao conceito de saúde os seus determinantes sociais em uma perspectiva de atenção integral às necessidades da população, superando o paradigma clínico de atenção às enfermidades, o que projetou uma nova divisão do trabalho, que atua em todas as funções inerentes à promoção, prevenção e reabilitação da saúde (8).

A Constituição de 1988 (1) absorveu os anseios da Reforma Sanitária na medida em que postulou a construção de uma sociedade mais justa e livre, baseada no 
aprofundamento da democracia participativa como principal mecanismo para se atingir a dignidade, a liberdade e a justiça social.

Posto isso, conforme Figueiredo (8), os conselhos de saúde aparecem enquadrados numa estratégia institucional que tem por finalidade abrir as portas do setor saúde à participação da sociedade civil organizada, reforçando assim a dinâmica social no sentido de sua organização em associações de interesse.

Figueiredo (8) coloca que para se alcançar esse objetivo é necessário ir além da diminuição das desigualdades sociais mediante melhor distribuição da renda. Considera necessário que também haja mudanças nos valores, atitudes e práticas que informam a consciência do cidadão. Sendo, em regra, considerado apenas consumidor, o cidadão deve passar a agir como executor e "desfrutador" da execução e do desenvolvimento de suas capacidades. E diz que, para isso, é necessário fortalecer na sociedade o sentido de "comunidade cívica" detentora de uma "cultura cívica".

Cultura cívica é aquela que sustenta orientações políticas participativas, nas quais o indivíduo, além de orientado para os mecanismos de ingresso no sistema político, tem conhecimento dos processos e estruturas do sistema de maneira geral. Dele se espera que esteja envolvido nas questões políticas de forma racional, que seja bem informado, confiante e alocado em um sistema político democrático (7).

Originou-se, assim, o Sistema Único de Saúde (SUS), como parte substantiva de um grande 'Projeto de Nação' chamado Brasil, como direito constitucional e regulamentado pelas Leis 8.080/90 (9) e 8.142/90 (2), esta última tratando da participação da comunidade na gestão do Sistema Único de Saúde através das Conferências de Saúde e dos Conselhos de Saúde.

A composição dos conselhos deve ser paritária e seus representantes devem compor em $50 \%$ de conselheiros usuários, $25 \%$ de trabalhadores de saúde e $25 \%$ de gestores e prestadores de serviços ao sistema. Observe-se que o maior percentual de participação é de usuários, pois configuram os destinatários da política de saúde.

Coelho et al (6) afirmam que, sob certas condições de estruturação dos processos participativos de organização da sociedade civil e de envolvimento dos gestores públicos, ocorrem ganhos redistributivos e aumento da participação de setores sociais tradicionalmente marginalizados. Destaca ainda a importância dos processos de 
mobilização para garantir o direito à participação dos atores que possuem menos recursos.

\section{O Conselho Regional de Saúde de Ceilândia}

Ceilândia é uma região administrativa do Distrito Federal criada a partir da Campanha de Erradicação das Invasões (CEI) empreendida durante a década de 70, localizada nas antigas terras da Fazenda Guariroba ao norte de Taguatinga. Sua população foi inicialmente composta pelos moradores da Vila do IAPI, das Vilas Tenório, Esperança, Bernardo Sayão e Colombo; dos morros do Querosene e do Urubu; e Curral das Éguas e Placa das Mercedes, as quais já contavam com mais de oitenta mil moradores àquela época (10).

Atualmente com mais de 398.374 habitantes (12), Ceilândia é a região administrativa de maior população do Distrito Federal, e a cidade mais nordestina do Distrito Federal (DF).

A cidade foi dividida originalmente em três grandes áreas: Ceilândia Norte, Ceilândia Centro, Ceilândia Sul e Guariroba (esses três primeiros, juntamente com parte da Guariroba, formavam o setor tradicional).

Ceilândia hoje é subdividida em diversos outros bairros, como: Setor "O", Expansão, P Norte, P Sul, QNQ e QNR, que em sua grande maioria, são densamente povoados.

Ceilândia tem uma economia forte, baseada principalmente no comércio e na indústria, sendo considerada também um celeiro cultural e esportivo, por conta de sua riquíssima diversidade artística e pelos atletas da cidade que despontam no cenário nacional e mundial. (11).

O Setor de Indústrias de Ceilândia é um dos principais do Distrito Federal. As maiores fábricas são de pré-moldados, alimentos e móveis.

Ceilândia é a região administrativa com o maior número de comerciários do DF (100 mil), possui uma população economicamente ativa de 160 mil pessoas e pode-se verificar também uma grande quantidade de feiras na região, como a Feira Central - a principal, exemplo de um empreendimento informal, pelo qual a cidade também pode se fortalecer. (11). 
As chamadas "Estradas Parques" fazem a ligação rodoviária entre Ceilândia e Brasília. São três as vias de acesso: DF 085 Estrada Parque Taguatinga (EPTG), ou "Linha Verde", DF 095 Estrada Parque Ceilândia (EPCL), ou "Via Estrutural" e DF 075 Estrada Parque Núcleo Bandeirante (EPNB).

A rodovia federal BR-070, que margeia o setor norte da cidade, dá acesso aos municípios goianos de Águas Lindas de Goiás e Pirenópolis.

Ceilândia é servida por cinco estações do Metrô do Distrito Federal: Ceilândia Sul, Guariroba, Ceilândia Centro, Ceilândia Norte e Ceilândia. Outras duas encontram-se em construção. Há vários terminais de ônibus urbanos, de onde partem ônibus para várias cidades do DF.

A Regional de Saúde de Ceilândia conta com um hospital regional e doze centros de saúde. Em Ceilândia o movimento pela saúde teve início antes de sua transferência, pois juntamente com a luta pelo direito à moradia regular estavam também as lutas por escolas e unidades de saúde dentre outras, porém em um cenário de repressão política e cultural e desigualdades sociais muito acentuadas. Por ocasião de sua transferência, intensificou-se a participação popular pela obtenção de serviços de saúde, antes inexistentes naquele local.

Tal movimento teve por conquista de suas reivindicações o Centro de Saúde nํ01, inaugurado em 1973. Porém, o Conselho Regional de Saúde de Ceilândia só foi instalado no ano de 1996 quando o Partido dos Trabalhadores ganhou as eleições para o governo do Distrito Federal. Como afirma Romão Neto (7), esta política era usual nas localidades em que o Partido dos Trabalhadores governava, pois tem por prática criar canais de interlocução com a sociedade.

Em 1999, o Partido dos Trabalhadores perdeu a eleição distrital. Os registros do Conselho Regional de Saúde de Ceilândia do período compreendido entre 1999 e 2002 não foram encontrados.

Assim, só em 2002, o Conselho Regional de Saúde de Ceilândia voltou a desenvolver seus trabalhos e, na abertura do livro ata do conselho, ficou registrada a seguinte observação: "ressalto que ao iniciar este trabalho, não foi localizado o livro ata anterior e nem os demais documentos do Conselho Regional de Saúde de Ceilândia. Ceilândia, 15 de outubro de 2002". 
Atualmente, o CRSC é um dos dezenove conselhos regionais de saúde em funcionamento no Distrito Federal.

\section{Metodologia}

Tratou-se de um estudo de caso - a atuação do Conselho Regional de Saúde de Ceilândia, no período de 2010/2011 -, qualiquantitativo, realizado a partir de análise documental, consubstanciada nas atas do referido conselho.

Empreendeu-se uma investigação empírica sobre a participação dos conselheiros de saúde do CRSC no processo que se convencionou chamar de controle social do SUS. Foram utilizadas como fontes de informação as atas das reuniões e das convocatórias no período de 2010/2011, bem como o regimento interno do conselho.

O CRSC é composto por dezesseis conselheiros titulares e dezesseis suplentes. A população definida para este estudo foi composta pelo total de membros conselheiros titulares componentes do CRSC, ou seja, os dezesseis membros.

As variáveis utilizadas foram: a frequência média das reuniões ordinárias e extraordinárias do conselho estudado; o exercício da presidência de seus trabalhos; a frequência média dos participantes distribuídos segundo segmento (representantes dos gestores, trabalhadores e usuários); a relação pauta prevista/realizada; propositores das pautas e deliberações e beneficiários das deliberações.

Realizou-se o lançamento dessas informações em um banco de dados no aplicativo Excel 2010 e, posteriormente, os mesmos foram transferidos para uma tabela do aplicativo Word 2010.

Os dados apresentados foram obtidos a partir do cálculo da média aritmética simples e do desvio padrão nas séries numéricas analisadas.

\section{Resultados}

O quadro 1 trata da frequência de realização das reuniões ordinárias e extraordinárias do CRSC, bem como da presidência de seus trabalhos. 
Quadro 1 - Reuniões do Conselho Regional de Saúde de Ceilândia no período 2010/2011

\begin{tabular}{|c|c|c|c|c|c|c|c|}
\hline \multirow[b]{2}{*}{ DATA } & \multicolumn{2}{|c|}{ ORDINÁRIA } & \multicolumn{2}{|c|}{ PRESIDÉNCIA } & \multirow[b]{2}{*}{ Extraordinária } & \multicolumn{2}{|c|}{ PRESIDÊNCIA } \\
\hline & Realizada & $\begin{array}{c}\text { Não } \\
\text { Realizada }\end{array}$ & Pres. & Mesa & & Pres. & Mesa \\
\hline \multicolumn{8}{|c|}{2010} \\
\hline $13 / 01 / 10$ & $\bar{X}$ & & $\bar{x}$ & & & & \\
\hline $29 / 01 / 10$ & $\mathrm{X}$ & & $\mathrm{X}$ & & & & \\
\hline $02 / 2010$ & & $\mathrm{X}$ & & & & & \\
\hline $03 / 2010$ & & $\mathrm{X}$ & & & & & \\
\hline $12 / 04 / 10$ & $\mathrm{X}$ & & $\mathrm{X}$ & & & & \\
\hline $05 / 2010$ & & $\mathrm{X}$ & & & & & \\
\hline $06 / 2010$ & & $\mathrm{X}$ & & & & & \\
\hline $07 / 2010$ & & $\mathrm{X}$ & & & & & \\
\hline $16 / 08 / 10$ & $\mathrm{X}$ & & $\mathrm{X}$ & & & & \\
\hline $13 / 09 / 10$ & & & & & $\mathrm{x}$ & $x$ & \\
\hline $20 / 09 / 10$ & $\mathrm{X}$ & & $\mathrm{X}$ & & & & \\
\hline $19 / 10 / 10$ & $\mathrm{X}$ & & $\bar{x}$ & & & & \\
\hline $22 / 11 / 10$ & $x$ & & $\mathrm{x}$ & & & & \\
\hline $13 / 12 / 10$ & $\mathrm{X}$ & & $\mathrm{X}$ & & & & \\
\hline \multicolumn{8}{|c|}{2011} \\
\hline $31 / 01 / 11$ & $\mathrm{X}$ & & $\mathrm{x}$ & & & & \\
\hline $14 / 02 / 11$ & & & & & $\bar{X}$ & & $\bar{x}$ \\
\hline $21 / 02 / 11$ & $x$ & & & $\bar{x}$ & & & \\
\hline $03 / 03 / 11$ & & & & & $\bar{X}$ & & $\bar{x}$ \\
\hline $28 / 03 / 11$ & $\mathrm{X}$ & & $x$ & & & & \\
\hline $01 / 04 / 11$ & & & & & $\bar{X}$ & & $\bar{x}$ \\
\hline $18 / 04 / 11$ & & & & & $\bar{X}$ & & $\bar{x}$ \\
\hline $26 / 05 / 11$ & $\bar{X}$ & & & $\bar{X}$ & & & \\
\hline $30 / 05 / 11$ & & & & & $\mathrm{x}$ & & $\bar{x}$ \\
\hline $30 / 06 / 11$ & $\mathrm{X}$ & & $\mathrm{X}$ & & & & \\
\hline $07 / 2011$ & & $\bar{X}$ & & & & & \\
\hline $04 / 08 / 11$ & $\bar{X}$ & & $\bar{X}$ & & & & \\
\hline $15 / 09 / 11$ & $\mathrm{X}$ & & $\bar{x}$ & & & & \\
\hline $14 / 10 / 11$ & $\mathrm{X}$ & & $\mathrm{X}$ & & & & \\
\hline $03 / 11 / 11$ & $\bar{X}$ & & $\mathrm{X}$ & & & & \\
\hline $12 / 2011$ & & $\mathrm{X}$ & & & & & \\
\hline
\end{tabular}

Fonte: Elaborado pela autora com base nas atas das reuniões ordinárias do CRSC. 
Observou-se que ocorreram 17 reuniões ordinárias e 7 reuniões extraordinárias no período (13).

O Regimento interno do conselho prevê a realização de 24 reuniões ordinárias, o que aparentemente não foi respeitado. Porém, nesse ínterim, ocorreram reuniões extraordinárias para emendar o Regimento interno; para preservar áreas já destinadas para construção de unidades de saúde; eleição do presidente do CRSC e composição da comissão organizadora das pré-conferências de saúde; e uma reunião preparatória da XIV Conferência Nacional de Saúde.

Neste ponto, torna-se importante perceber que, apesar de não terem ocorrido todas as reuniões ordinárias como previsto no $\mathrm{Rl}$, com a realização das 7 reuniões extraordinárias manteve-se o intervalo médio de trinta dias entre elas. Sendo assim, conclui-se que o regimento foi respeitado tanto no número de reuniões quanto no intervalo entre elas.

Quanto à presidência dos trabalhos nestas reuniões, note-se que 16 foram presididas pelo presidente do CRSC e oito pela Mesa Diretora.

O Regimento Interno do CRSC prevê que na ausência do presidente as reuniões devem ser presididas pela Mesa Diretora, a qual é composta por representantes dos segmentos gestor, trabalhador e usuário. Sendo assim, em 7 ocasiões, foi o que ocorreu.

A flutuação ocorrida na presidência das reuniões do Conselho no período analisado decorre em grande parte da ausência de presidente eleito pelo plenário. Por meio da leitura das atas é possível constatar que a cada mudança do gestor designado para chefiar a Regional de Saúde de Ceilândia, o CRSC era obrigado a refazer o processo de indicação e eleição do presidente do conselho, transferindo a condução dos trabalhos nessas ocasiões à mesa diretora. O que permite inferir que era tradição no CRSC a presidência ser ocupada pelo diretor da Regional de Saúde.

Tal fato permitiu que, por diversas ocasiões, não se realizasse reuniões regulares ou adiasse os encontros justamente pelo esvaziamento do segmento gestor do colegiado. A situação persistiu até a indicação e eleição para o cargo de presidente de um representante do segmento trabalhador. 
Esse fato demonstra que o CRSC já vem avançando no sentido de afastar a presidência do conselho da gestão do sistema de forma que suas decisões se aproximem mais do princípio da participação popular previsto na Constituição Federal, mas trata-se de tema polêmico na medida em que, no período 2011/2012, o Conselho Nacional de Saúde foi presidido pelo Ministro da Saúde.

Como o presidente, quando eleito, esteve presente nas reuniões e as coordenou, conclui-se que o Regimento Interno foi respeitado também neste quesito.

Quadro 2 - frequência média dos participantes por segmento no período 2010/2011.

\begin{tabular}{|c|c|c|c|c|c|c|c|c|c|c|c|c|c|c|c|c|}
\hline Reunião & \multicolumn{8}{|c|}{ Usuário } & \multicolumn{4}{|c|}{ Trabalhador } & \multicolumn{4}{|c|}{ Gestor } \\
\hline Datas & 1 & 2 & 3 & 4 & 5 & 6 & 7 & 8 & 1 & 2 & 3 & 4 & 1 & 2 & 3 & 4 \\
\hline $13 / 01 / 10$ & $X$ & $X$ & $X$ & $X$ & $X$ & $X$ & $X$ & $X$ & $X$ & & & & & & & \\
\hline $29 / 01 / 10$ & $X$ & $x$ & $X$ & $X$ & $\mathrm{X}$ & $X$ & $X$ & $X$ & & & & & $x$ & & & \\
\hline $12 / 04 / 10$ & $X$ & $\bar{x}$ & $X$ & $X$ & $X$ & $X$ & $\mathrm{X}$ & & $x$ & $x$ & & & $X$ & & & \\
\hline $16 / 08 / 10$ & $\mathrm{X}$ & $x$ & $x$ & $x$ & & & & $X$ & $X$ & $x$ & $x$ & $x$ & $\mathrm{X}$ & $x$ & $\mathrm{X}$ & \\
\hline $13 / 09 / 10$ & $X$ & $\bar{X}$ & $X$ & & & & & & $\bar{X}$ & $X$ & $X$ & $X$ & $X$ & $X$ & $\bar{X}$ & $\bar{X}$ \\
\hline $20 / 09 / 10$ & $\mathrm{X}$ & $\mathrm{X}$ & $X$ & $\mathrm{X}$ & $\bar{X}$ & $\bar{X}$ & $\bar{X}$ & $\bar{X}$ & $\bar{X}$ & $\bar{X}$ & $\bar{X}$ & $X$ & $\mathrm{X}$ & $\mathrm{X}$ & & \\
\hline 19/10/10 & $\bar{X}$ & $\bar{X}$ & $\bar{x}$ & $x$ & & & & & $\bar{X}$ & $\bar{X}$ & $\bar{X}$ & $x$ & $\mathrm{X}$ & $\bar{X}$ & $X$ & $\bar{x}$ \\
\hline $22 / 11 / 10$ & $\bar{X}$ & $\bar{x}$ & $\bar{x}$ & $\bar{x}$ & & & & & $\mathrm{X}$ & $\mathrm{X}$ & $\mathrm{X}$ & $\mathrm{X}$ & $\bar{x}$ & $\bar{x}$ & $\bar{X}$ & \\
\hline $13 / 12 / 10$ & $\bar{x}$ & $\mathrm{X}$ & $\mathrm{x}$ & $\bar{x}$ & $\bar{x}$ & $\bar{x}$ & $\mathrm{X}$ & & $x$ & $x$ & $x$ & $x$ & $x$ & $\mathrm{X}$ & $\bar{x}$ & $x$ \\
\hline $31 / 01 / 11$ & $\bar{X}$ & $\bar{x}$ & $x$ & $X$ & $X$ & $X$ & & & $\bar{X}$ & $\bar{x}$ & $X$ & $X$ & $\bar{X}$ & $\bar{x}$ & $\bar{X}$ & \\
\hline $14 / 02 / 11$ & $\bar{x}$ & $\bar{x}$ & $\bar{x}$ & $\bar{x}$ & $\bar{x}$ & $X$ & $\bar{x}$ & & $\bar{x}$ & $X$ & $X$ & & $X$ & $\bar{x}$ & $\bar{x}$ & $\bar{x}$ \\
\hline $21 / 02 / 11$ & $\bar{x}$ & $\mathrm{X}$ & $\bar{x}$ & $\bar{X}$ & $\bar{X}$ & & & & $x$ & $x$ & $x$ & $x$ & $x$ & $x$ & $\bar{X}$ & \\
\hline $03 / 03 / 11$ & $\bar{x}$ & $\bar{x}$ & $\bar{x}$ & $\bar{X}$ & $\bar{X}$ & $x$ & & & $\bar{X}$ & $\bar{x}$ & $\bar{x}$ & $\bar{X}$ & $\mathrm{X}$ & $\bar{x}$ & $\bar{X}$ & $\bar{x}$ \\
\hline $28 / 03 / 11$ & $\bar{x}$ & $\bar{X}$ & $\bar{x}$ & $\bar{x}$ & $\bar{X}$ & $\bar{x}$ & & & $\bar{x}$ & $x$ & $x$ & & $\bar{x}$ & $\bar{x}$ & $\bar{X}$ & $\bar{X}$ \\
\hline $01 / 04 / 11$ & $\bar{x}$ & 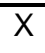 & $\bar{x}$ & $x$ & $\bar{X}$ & & & & $x$ & $x$ & & & $x$ & 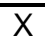 & $x$ & $\mathrm{X}$ \\
\hline $18 / 04 / 11$ & $\bar{x}$ & $\bar{X}$ & $\bar{x}$ & $\bar{x}$ & & & & & $\bar{x}$ & $\bar{x}$ & $X$ & & $\bar{x}$ & $\bar{x}$ & $\bar{X}$ & \\
\hline $26 / 05 / 11$ & $\bar{x}$ & $\bar{x}$ & $\mathrm{x}$ & $x$ & $\bar{X}$ & $\bar{x}$ & $\bar{X}$ & & $\bar{X}$ & $\bar{X}$ & $\bar{X}$ & & $\bar{x}$ & $\bar{x}$ & $\bar{x}$ & $\mathrm{X}$ \\
\hline $30 / 05 / 11$ & $\bar{X}$ & $\bar{X}$ & $\bar{x}$ & $\bar{x}$ & & & & & $\bar{X}$ & $\bar{X}$ & & & $\bar{X}$ & $\bar{x}$ & $\bar{X}$ & \\
\hline $30 / 06 / 11$ & $\bar{X}$ & $\bar{X}$ & $\bar{x}$ & $\bar{x}$ & $\bar{X}$ & & & & $\bar{X}$ & $\bar{X}$ & & & $x$ & $\bar{x}$ & $\bar{X}$ & \\
\hline $04 / 08 / 11$ & $\bar{X}$ & $\bar{x}$ & $x$ & $x$ & $\bar{X}$ & $x$ & $\mathrm{X}$ & & $\bar{X}$ & $\mathrm{X}$ & $x$ & $x$ & $x$ & $\bar{X}$ & $\bar{x}$ & $\bar{x}$ \\
\hline $15 / 09 / 11$ & $\bar{x}$ & $\bar{x}$ & $x$ & $\bar{x}$ & $\bar{X}$ & $\bar{x}$ & & & $\bar{x}$ & $\bar{x}$ & & & $\bar{X}$ & $\bar{X}$ & & \\
\hline $14 / 10 / 11$ & $x$ & $x$ & $x$ & $\bar{x}$ & $\mathrm{X}$ & $x$ & & & $\bar{X}$ & $x$ & & & $x$ & $x$ & $x$ & $x$ \\
\hline $03 / 11 / 11$ & $\bar{X}$ & $\bar{X}$ & $\bar{X}$ & $\bar{X}$ & $\bar{X}$ & $\bar{X}$ & $\bar{X}$ & & $\bar{X}$ & $\bar{X}$ & $\bar{X}$ & & $\bar{X}$ & $\bar{X}$ & $\bar{X}$ & $\bar{X}$ \\
\hline
\end{tabular}

Fonte: Elaborado pela autora com base nas atas das reuniões ordinárias do CRSC. 
Gráfico 1 - frequência média por segmento

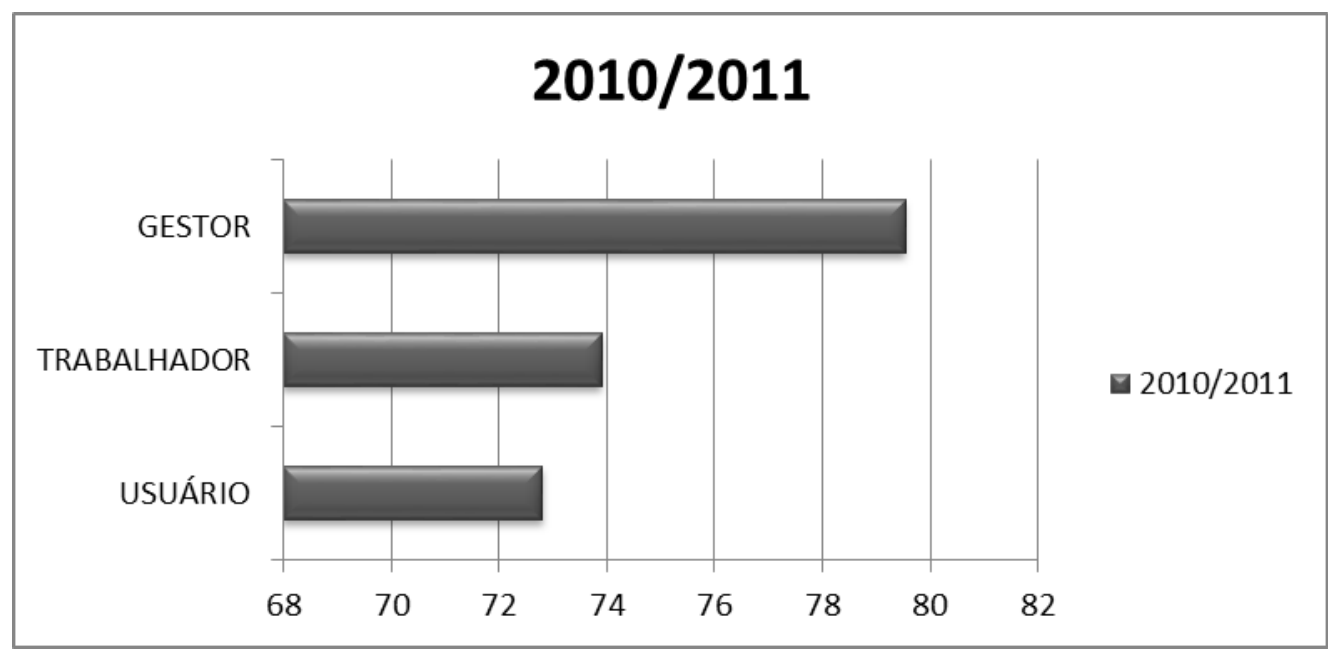

Fonte: Elaborado pela autora com base nas atas das reuniões ordinárias do CRSC. Os números apresentados estão em percentuais (1/100).

A partir das informações contidas no quadro 2, foi construído o gráfico 1 . Observou-se que a média geral de frequência do conjunto dos segmentos foi de $75,42 \%$, com desvio médio de $\pm 22,13 \%$.

No tocante à frequência por segmento, a distribuição ficou na seguinte ordem: o segmento usuário apresentou frequência de $72,81 \%$, o segmento trabalhador $73,91 \%$ e o segmento gestor $79,55 \%$.

Depreende-se do gráfico 1que a maior participação foi do segmento gestor, seguido do segmento trabalhador nas reuniões do Conselho Regional de Saúde de Ceilândia. São os executores das políticas públicas de saúde, o que pode decorrer de assimetrias informacionais. Também, demonstra que sendo conhecedores das exigências legais relacionadas às atribuições do cargo que ocupam, estão responsáveis pelas questões de interesse dos usuários.

Apesar de apresentar menor média de frequência nas reuniões do CRSC, $72,81 \%$, o segmento usuário teve presença bastante significativa e se aproximou da frequência dos outros seguimentos. Outro dado significativo é que $37,5 \%$ do segmento usuário estiveram $100 \%$ presente em todas as reuniões, seja ordinária ou extraordinária. Tal fato demonstra que há uma associação positiva entre participação popular enquanto princípio constitucional e participação real do seguimento usuário no conselho estudado. Demonstra também um nível bom de conexão entre os atores políticos e institucionais 
com os atores destinatários da política de saúde, o que possibilitará maior materialização do direito à saúde.

A tabela 3 mostra a relação pauta prevista/pauta realizada.

Quadro 3 - relação pauta prevista x pauta realizada no período 2011/2011.

\begin{tabular}{|c|c|c|c|}
\hline Data & Pauta prevista & Pauta Realizada & Média \\
\hline $13 / 01 / 2010$ & 1 item & 1 item & $100 \%$ \\
\hline $29 / 01 / 2010$ & 1item & 1item & $100 \%$ \\
\hline $12 / 04 / 2010$ & 3 itens & 5 itens & $166 \%$ \\
\hline $16 / 08 / 2010$ & 6 itens & 6 itens & $100 \%$ \\
\hline $20 / 09 / 2010$ & 10 itens & 10 itens & $100 \%$ \\
\hline $13 / 09 / 2010$ & 1 item & 1 item & $100 \%$ \\
\hline $19 / 10 / 2010$ & 9 itens & 10 itens & $111 \%$ \\
\hline $22 / 11 / 2010$ & 12itens & 10 itens & $83,33 \%$ \\
\hline $13 / 12 / 2010$ & 11 itens & 15 itens & $136,36 \%$ \\
\hline $31 / 01 / 2011$ & 9 itens & 7itens & $77,7 \%$ \\
\hline $14 / 02 / 2011$ & 4 item & 3 item & $75 \%$ \\
\hline $21 / 02 / 2011$ & 11 itens & 5 itens & $45,45 \%$ \\
\hline $03 / 03 / 2011$ & 6 item & 7 item & $116,66 \%$ \\
\hline $28 / 03 / 2011$ & 5 itens & 5 itens & $100 \%$ \\
\hline $01 / 04 / 2011$ & 11 itens & 17 itens & $154,54 \%$ \\
\hline $18 / 04 / 2011$ & 5 item & 5 item & $100 \%$ \\
\hline $26 / 05 / 2011$ & 11 itens & 4 itens & $36,36 \%$ \\
\hline $30 / 05 / 2011$ & 2 itens & 3 itens & $150 \%$ \\
\hline $30 / 06 / 2011$ & 7 itens & 7 itens & $100 \%$ \\
\hline 04/08/2011 & 7 itens & 7 itens & $100 \%$ \\
\hline $15 / 09 / 2011$ & 9 itens & 9 itens & $100 \%$ \\
\hline $14 / 10 / 2011$ & 10 itens & 10 itens & $100 \%$ \\
\hline 03/11/2011 & 10 itens & 7itens & $70 \%$ \\
\hline
\end{tabular}

Fonte: Elaborado pela autora com base nas atas das reuniões ordinárias do CRSC.

A média geral de cumprimento das pautas no período foi de 93,33\%. A pauta prevista da primeira reunião ocorrida em janeiro do ano de 2010 foi deduzida da própria ata da reunião realizada, pois nos documentos do CRSC não foi localizada. Como se 
tratava da composição do conselho, não poderia ter outro item de pauta, pois este estava em formação.

A mesma situação verificou-se nas reuniões de agosto e setembro do mesmo ano, ou seja, foi deduzida da própria ata.

A pauta da reunião de abril do mesmo ano foi lida no início dos trabalhos da reunião, conforme consta da própria ata.

Foram computados os itens inscritos nas respectivas atas das reuniões.

Sendo a média de cumprimento das pautas superior a noventa por cento, ficou demonstrado que foi bastante significativa a produção do CRSC.

Quadro 4 - propositura das pautas no período 2010/2011.

\begin{tabular}{|c|c|c|c|c|c|c|c|}
\hline DATA & Pautas & Gestor & Média & Trabalhadores & Media & Usuários & Media \\
\hline $13 / 01 / 2010$ & 1 & 0 & $0 \%$ & 1 & $100 \%$ & 0 & 0 \\
\hline $29 / 01 / 2010$ & 1 & 0 & $0 \%$ & 1 & $100 \%$ & 0 & $0 \%$ \\
\hline $05 / 01 / 1900$ & 5 & 5 & $100 \%$ & 0 & 0 & 0 & 0 \\
\hline $16 / 08 / 2010$ & 5 & 5 & $100 \%$ & 0 & 0 & 0 & 0 \\
\hline $13 / 09 / 2010$ & 2 & 1 & $50 \%$ & 0 & 0 & 0 & 0 \\
\hline $20 / 09 / 2010$ & 9 & 9 & $100 \%$ & 0 & 0 & 0 & 0 \\
\hline $19 / 10 / 2010$ & 8 & 5 & $63 \%$ & 2 & $25 \%$ & 1 & $13 \%$ \\
\hline $22 / 11 / 2010$ & 8 & 5 & $63 \%$ & 2 & $25 \%$ & 1 & $13 \%$ \\
\hline $13 / 12 / 2010$ & 14 & 6 & $42,85 \%$ & 7 & $50 \%$ & 1 & $0,71 \%$ \\
\hline $31 / 01 / 2011$ & 8 & 5 & $62,50 \%$ & 2 & $28,57 \%$ & 1 & $12,50 \%$ \\
\hline $14 / 02 / 2011$ & 3 & 2 & $67 \%$ & 1 & $33,33 \%$ & 0 & 0 \\
\hline $21 / 02 / 2011$ & 9 & 5 & $55,55 \%$ & 1 & $11,11 \%$ & 3 & $33,33 \%$ \\
\hline $03 / 03 / 2011$ & 7 & 2 & $28,57 \%$ & 3 & $42,85 \%$ & 1 & $14,28 \%$ \\
\hline $21 / 03 / 2011$ & 5 & 1 & $20 \%$ & 2 & $40 \%$ & 2 & $40 \%$ \\
\hline $01 / 04 / 2011$ & 15 & 4 & $26,66 \%$ & 6 & $40 \%$ & 5 & $33,33 \%$ \\
\hline $18 / 04 / 2011$ & 4 & 0 & $0,00 \%$ & 4 & $100 \%$ & 0 & $0,00 \%$ \\
\hline $26 / 05 / 2011$ & 9 & 4 & $44,44 \%$ & 2 & $22,22 \%$ & 3 & $33,33 \%$ \\
\hline $30 / 05 / 2011$ & 2 & 0 & $0,00 \%$ & 2 & $100 \%$ & 0 & $0,00 \%$ \\
\hline $30 / 06 / 2011$ & 5 & 0 & $0,00 \%$ & 2 & $40 \%$ & 3 & $60 \%$ \\
\hline $04 / 08 / 2011$ & 8 & 2 & $25 \%$ & 2 & $25 \%$ & 4 & $50 \%$ \\
\hline $15 / 09 / 2011$ & 9 & 2 & $22,22 \%$ & 3 & $33,33 \%$ & 4 & $44,44 \%$ \\
\hline $14 / 10 / 2011$ & 5 & 2 & $40 \%$ & 3 & $60 \%$ & 0 & $0,00 \%$ \\
\hline $03 / 11 / 2011$ & 8 & 3 & $37,50 \%$ & 2 & $25 \%$ & 3 & $37,50 \%$ \\
\hline MEDIA & & & $41 \%$ & & $39 \%$ & & $19 \%$ \\
\hline
\end{tabular}

Fonte: Elaborado pela autora com base nas atas das reuniões ordinárias e pautas do CRSC. 
No tocante à propositura das pautas (Quadro 4), foi possível observar que o segmento gestor propôs $41,51 \%$ dos itens para discussão, enquanto que o segmento trabalhador pautou $39 \%$, seguido pelo segmento usuário com $19,49 \%$ de proposições.

A análise do teor das discussões ocorridas durante as reuniões do CRSC e da quantidade de inserções realizadas já no desenvolvimento da reunião em relação ao número de itens inicialmente previstos para 0 debate refletem grande tendência à flexibilização da pauta prevista para o plenário. É recorrente a prática entre alguns conselheiros de sugerir temas para a discussão, sem comunicação prévia ao plenário, o que dificulta, por vezes, a análise mais acurada do assunto e a tomada de deliberações com maior fundamentação legal.

O resultado geralmente ressoa na grande necessidade de realização de reuniões extraordinárias para discussão do assunto intempestivo ou prejuízo do debate de outros temas já previstos para apreciação do plenário.

Em toda reunião ordinária, ao menos dois itens são regimentais. Portanto, não foram atribuídos a um segmento específico. Trata-se da aprovação da ata da reunião anterior e aprovação da pauta preliminar. Sendo assim, não entraram no cálculo apresentado no gráfico acima.

Estudos (14) observaram que as relações entre os atores são marcadas por assimetrias informacionais de forma que os agentes estatais acabam por dominar os fóruns participativos, o que pode ser observado no quadro 4 , pois as médias de propositura de pautas dos gestores e dos trabalhadores foi a mais expressiva. Além disso, as inserções por parte dos usuários são mais de informes que de debates.

Tal fato, à luz dos princípios do controle social e da participação da sociedade na construção do SUS, precisa ser melhor estudado, uma vez que o segmento usuário é a maior representação nos conselhos de saúde. 
Gráfico 2 - informes no período 2010/2011.

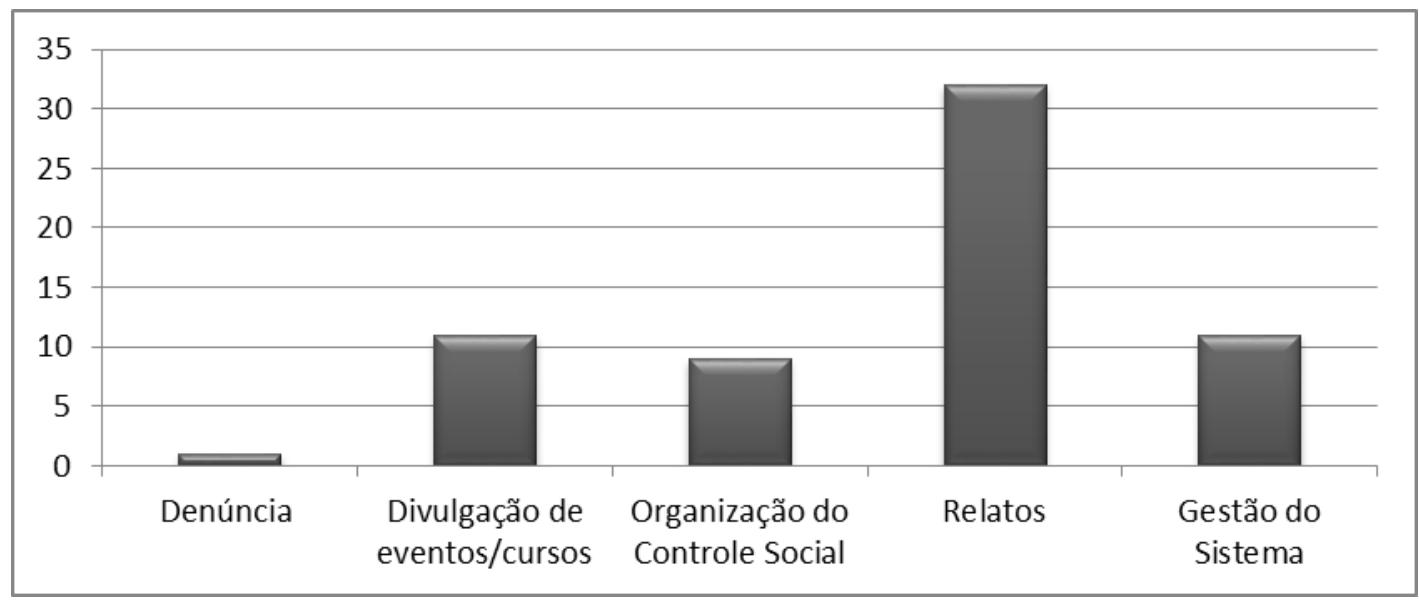

Fonte: Elaborado pela autora com base nas atas das reuniões ordinárias e pautas do CRSC.

O conjunto das atas objeto deste estudo demonstra que as discussões giraram em torno de cinco tipos de informes: denúncia, divulgação de eventos e cursos, organização do controle social, relatos e gestão do sistema.

Observa-se que grande parte dos informes deteve-se na apresentação de relatos, especialmente, no tocante ao controle social. Foram exposições dos conselheiros a respeito da participação em atividades voltadas para o controle social e/ou atuação na formulação de políticas públicas na área da saúde, além da resolução de conflitos.

Destacou-se a apresentação de informes relacionados à divulgação de eventos/cursos, sendo estes voltados para a formação dos conselheiros, com foco educativo, sociopolítico e/ou cultural, que objetivaram a capacitação e a troca de experiências.

A organização do próprio conselho também ficou bastante evidenciada no gráfico acima, pois tais informes tratavam de questões relacionadas ao funcionamento administrativo do colegiado, entre elas, emissão de documentos, inscrições em atividades, suporte ao trabalho das comissões, dentre outras informações pertinentes.

É importante observar, a partir do gráfico acima, que a gestão se preocupou em informar aos conselheiros dados referentes ao funcionamento das unidades de saúde, tais como melhorias implantadas, projetos em andamento e aperfeiçoamento na oferta de serviços. 
Por fim, há que se questionar o caso das denúncias, que não figuraram expressivamente nas atas. Foi possível perceber a formalização de apenas uma denúncia no período, o que não significa que outras denúncias não tenham ocorrido, sem registro, durante as discussões e debates nas reuniões do Conselho.

\section{Considerações finais}

Há um denso debate sobre o papel que a participação social pode desempenhar na democratização do acesso às políticas públicas, assim como as condições para esta participação. No entanto, não existem instrumentos metodológicos que possibilitem comparar tais experiências de maneira sistemática.

Procurou-se avançar nessa questão mediante um estudo empírico, buscando examinar os processos pelos quais a participação social pode democratizar o acesso às deliberações sobre políticas públicas e consequentemente materializar o direito à saúde.

Trabalhou-se com um pequeno número de conselheiros e o grau de detalhe das atas dependia da precisão do secretário executivo - fatores que limitaram o escopo do estudo. Apesar dessas limitações, abordou-se um conjunto de variáveis, algumas já descritas na literatura, que permitiram delinear uma visão geral do desempenho do CRSC.

Como visto, o CRSC atua em área periférica de Brasília, capital do país, e, embora não seja município, é "equiparada" a este por força da Lei Orgânica do Distrito Federal, que o considera uma das instâncias colegiadas componentes do SUS no Distrito Federal.

Os resultados indicaram que há uma associação positiva entre participação popular enquanto princípio constitucional e participação real do segmento usuário no conselho estudado. Demonstrou-se um nível bom de conexão entre os atores políticos e institucionais com os atores destinatários da política de saúde.

Concluiu-se que o regimento foi respeitado em todos os aspectos pesquisados: tanto no número de reuniões quanto no intervalo entre elas, bem como na presidência dos trabalhos.

O nível de participação dos segmentos que compõem o conselho foi bastante expressivo, pois esteve entre setenta e oitenta por cento na média geral de frequência. 
Tal fato demonstrou que o direito de participação na gestão local do Sistema de Saúde está sendo respeitado. A maior participação nas reuniões em análise foi do segmento gestor, seguido do segmento trabalhador. Concomitantemente, devido ao problema de assimetrias informacionais, o segmento que mais pautou as reuniões do CRSC foi o gestor. Porém, é possível inferir, a partir dos temas propostos nas pautas, que o interesse defendido, em geral, contemplava direitos dos usuários.

Apesar de apresentar menor média de frequência nas reuniões do Conselho, foi o segmento usuário que apresentou conselheiros com $100 \%$ de frequência em todas as reuniões, seja ordinária ou extraordinária.

Os autores citados na revisão bibliográfica observaram em suas pesquisas: uma associação positiva entre participação popular enquanto princípio constitucional e participação real do seguimento usuário no conselho estudado. Há alinhamento com as observações dos autores citados na revisão bibliográfica na medida em que há a estruturação do espaço público e político de discussão e deliberação acerca das ações de saúde para aquela localidade: o Conselho Regional de Saúde de Ceilândia reúne-se regularmente, ou seja, assume seu papel de mecanismo capaz de promover maior envolvimento dos cidadãos, maior transparência e um fluxo de informações estratégico entre o ofertante e os demandantes de saúde na regional.

Estão abertas as portas do setor saúde à participação da sociedade civil organizada na Regional de Saúde da Ceilândia, tal como é esperado desde as reformas setoriais que culminaram na criação do SUS. 


\section{Referências}

1 Brasil. Constituição da República Federativa do Brasil de 1988. Brasília: Senado Federal, 2013.

2 Brasil. Lei 8142 de 28 de dezembro de 1990. Dispõe sobre a participação da comunidade na gestão do Sistema Único de Saúde (SUS\} e sobre as transferências intergovernamentais de recursos financeiros na área da saúde e dá outras providências.

3 Alves, SMC. Processo de Participação da sociedade civil nas consultas públicas realizadas pela Agência Nacional de Vigilância Sanitária. Dissertação defendida junto ao Departamento de Serviço Social da Universidade de Brasília-UnB, 2006.

4 Brasil. Ministério da Saúde. Relatório Final da Oitava Conferência Nacional de Saúde Mental. Brasília: Centro de Documentação do Ministério da Saúde do Brasil, 1986, p. 4

5. Distrito Federal. Administração Regional de Ceilândia. Apresentação Ceilândia - RA IX. [ Acesso em 12 out 2012]. Disponível em: http://www.ceilandia.df.gov.br/sobre-a-raix/conheca-ceilandia-ra-ix.html.

6. Coelho, VSP; Ferraz, A; Fanti, F e Ribeiro, M. Mobilização e participação: um jogo de soma zero? [ Acesso em 19 nov 2012]. Disponível em:

http://www.scielo.br/scielo.php?pid=S0101-33002010000100007\&script=sci_arttext.

7 Romão Neto, JV. Participação popular em saúde: o caso dos conselhos gestores das subprefeituras de São Paulo. São Paulo: USP, 2006.

8 Figueiredo, JESA. Comunidade Cívica, Capital Social e Conselhos de Saúde no Estado do Rio de Janeiro. Rio de Janeiro: Ensp/Fiocruz, 2001

9 Brasil. Lei Federal 8080 de 19 de setembro de 1990. Dispõe sobre as condições para a promoção, proteção e recuperação da saúde, a organização e o funcionamento dos serviços correspondentes e dá outras providências. [Acesso em 12.jan.2016]. Disponível em http://www.planalto.gov.br/ccivil_03/Leis/L8080.htm

10 Distrito Federal. Companhia de Planejamento do Distrito Federal. Coletânea de Informações Socioeconômicas - Ceilândia (PDF). Maio de 2007. [ Acesso em 30 out 2012]. Disponível em: http://www.codeplan.df.gov.br/menu-de-teste/informacoesestatisticas/cat_view/262-informacoes-estatisticas/271-regioes administrativas-do-df-coletanea-de-informacoes-socioeconomicas-2007-.html?start=5.

11 Distrito Federal. Companhia de Planejamento do Distrito Federal. Pesquisa Distrital por Amostra de Domicílios - 2010/2011 (PDAD). [ Acesso em 30 out 2012]. Disponível em:

http://www.codeplan.df.gov.br/images/CODEPLAN/PDF/Pesquisas\%20Socioeconômica s/PDAD/2011/PDAD\%20Ceilândia-2010-2011.pdf.

12 Distrito Federal. Secretaria de Planejamento e Orçamento do Governo do Distrito Federal. Ranking decrescente do IDH-M das Regiões Administrativas do Distrito Federal. (2000). [ Acesso em 22 jul 2012]. Disponível em:

http://www.seplan.df.gov.br/005/00502001.asp?ttCD_CHAVE=1621\#1. Acesso em: 22 de julho de 2012. 
13 Distrito Federal. Conselho Regional de Saúde de Ceilândia. Abertura do livro ata. Ceilândia: outubro de 2002.

14 Sposati, A e Lobo, E. Controle Social e Políticas de Saúde. Cad. Saúde Pública. Rio de Janeiro, 8 (4): 366-378, out/dez, 1992 